\title{
Clinical characteristics and fatal outcomes of hypertension in patients with severe COVID-19
}

\author{
Xiaocheng Cheng ${ }^{1,{ }^{*}}$, Guoqiang Cai ${ }^{2,}{ }^{*}$, Xuesong Wen ${ }^{1}$, Lei Gao ${ }^{1}$, Dan Jiang ${ }^{1}$, Min Sun ${ }^{1}$, Shu Qin ${ }^{1}$, \\ Jianzhong Zhou ${ }^{1}$, Dongying Zhang ${ }^{1}$ \\ ${ }^{1}$ Department of Cardiology, The First Affiliated Hospital of Chongqing Medical University, Chongqing 400016, \\ China \\ ${ }^{2}$ Department of Emergency, Traditional Chinese Medicine Hospital Dianjiang Chongqing, Chongqing 408300, China \\ *Equal contribution
}

Correspondence to: Jianzhong Zhou, Dongying Zhang; email: 13108985803@hospital.cqmu.edu.cn, zhangdongying@cqmu.edu.cn

Keywords: COVID-19, hypertension, ACEI/ARB, mortality, cardiac injury

Received: May 19, $2020 \quad$ Accepted: August 19, $2020 \quad$ Published: November 16, 2020

Copyright: (c) 2020 Cheng et al. This is an open access article distributed under the terms of the Creative Commons Attribution License (CC BY 3.0), which permits unrestricted use, distribution, and reproduction in any medium, provided the original author and source are credited.

\section{ABSTRACT}

The aim of this study is to investigate clinical characteristics and fatal outcomes of hypertension as well as the role of angiotensin-converting enzyme inhibitors/angiotensin receptor blockers (ACEI/ARB) use in patients with severe coronavirus disease 2019 (COVID-19). A total of 220 (female: 51.8\%) patients with severe COVID-19 were included. The mean age of included patients was 59.5 years and 70 (31.8\%) patients had a history of hypertension. There were 23 patients (32.9\%) receiving ACEI/ARB therapy. Patients with hypertension were older and had more comorbidities, and were more likely to suffer from severe inflammatory response and acute cardiac injury. Moreover, patients with hypertension were associated with significantly higher risk of inhospital mortality than patients without hypertension. After adjustment of potential confounders, the independent correlation was still observed. In addition, ACEI/ARB users were associated with lower level of high-sensitivity cardiac troponin I and creatinine kinase-myocardial band, and lower risk of acute cardiac injury than ACEI/ARB non-users. In conclusion, patients with hypertension were more likely to suffer from severe inflammatory response, acute cardiac injury and had high risk of in-hospital mortality in severe COVID-19. The use of ACEI/ARB may protect patients with COVID-19 from acute cardiac injury.

\section{INTRODUCTION}

The coronavirus disease 2019 (COVID-19) has become a worldwide pandemic [1-4]. Some studies have reported information on the epidemiology and clinical features of COVID-19, which suggested that COVID19 can cause acute respiratory distress syndrome (ARDS), multiple organ dysfunction syndrome and 2 to $21 \%$ risk of death $[1-4,5]$. It has been shown that hypertension was one of the most distinctive comorbidities in COVID-19 infection. The study by Guan and colleagues enrolled 1099 patients with confirmed COVID-19, $23 \%$ of whom had a history of hypertension in severe cases [1]. Richardson et al. reported that hypertension was the most common comorbidities in COVID-19, reaching to $56.6 \%$ [4]. However, it is unclear about the clinical characteristics of hypertension infected COVID-19, and whether hypertension is associated with poor clinical outcomes is also less clear.

Notably, hypertension may frequently be treated with angiotensin converting enzyme inhibitors (ACEI)/ angiotensin receptor blockers (ARB) [6-7]. But the administration of ACEI/ARB in COVID-19 was controversial. Some researchers have put forward the 
hypothesis that ACEI/ARB might become a potential risk factor for fatal COVID-19 by up-regulating the expression of angiotensin-converting enzyme 2 (ACE2) [8-9]. In view of the overwhelming evidence of mortality reduction in cardiovascular disease, however, some investigators suggested that ACEI/ARB therapy should be maintained or initiated in patients with hypertension according to current guidelines [10].

Up to date, there are limited clinical studies evaluating the safety of ACEI/ARB in the treatment of COVID-19 with hypertension. The purpose of this study was to investigate clinical characteristics and outcomes of hypertension as well as the role of ACEI/ARB in severe COVID-19.

\section{RESULTS}

\section{Baseline characteristics and laboratory findings}

The study initially enrolled $237 \quad(51.8 \%$ female $)$ consecutive patients with severe COVID-19. We excluded 14 discharged patients and 3 patients who died because of incomplete data, leaving 220 patients for final analysis. The median age of included patients was 59.5 years (range 24 to 94 years). Sixty-two (31.8\%) patients coexisted with hypertension. Patients with severe COVID-19 with hypertension were more likely to be older (median [IQR], 68.5 [60.8-77.0] vs 54.5 [41.0-65.3] years; $\mathrm{P}<0.001)$ and to have previous coronary artery disease (16 of 70 [22.9\%] vs 6 of 150 [4.0\%]; $\mathrm{P}<0.001)$, and were more likely to be exhibit dyspnea (38 of 70 [54.3\%] vs 56 of 150 [37.3\%]; P < $0.001)$ and have a higher systolic blood pressure (median [IQR], 130 [122-144] vs 121 [115-131] mmHg; $\mathrm{P}=0.001$ ) at admission (Table 1). There was no significant discrepancies in other signs and symptoms between the two groups.

In terms of laboratory findings, patients with hypertension compared with patients without hypertension showed higher median creatinine kinasemyocardial band (CK-MB, median [IQR], 2.04 [1.02$3.61] \mathrm{ng} / \mathrm{mL}$ vs $0.95 \quad[0.60-2.12] \mathrm{ng} / \mathrm{mL})$, highsensitivity cardiac troponin I (hs-cTnI, median [IQR], 17 [0-71] $\mathrm{pg} / \mathrm{ml}$ vs $<6 \mathrm{pg} / \mathrm{ml})$, N-terminal pro-B-type natriuretic peptide (median [IQR], 537.8 [172.6-1340.5] $\mathrm{pg} / \mathrm{mL}$ vs 120.2 [36.7-391.9] pg/mL), white blood cell count (median [IQR], 6260 [4400-8200] cells/ $\mu \mathrm{L}$ vs 5170 [3950-6700] cells $/ \mu \mathrm{L}$ ), and levels of D-dimer (median [IQR], 1.83 [0.56-8.90] $\mathrm{mg} / \mathrm{L}$ vs 0.61 [0.361.98] $\mathrm{mg} / \mathrm{L}$ ), creatinine (median [IQR], 69 [51-84] $\mu \mathrm{mol} / \mathrm{L}$ vs 59 [49-72] $\mu \mathrm{mol} / \mathrm{L})$ and lower estimated glomerular filtration rate (eGFR) (median [IQR], 89.3 [58.3-99.1] $\mu \mathrm{mol} / \mathrm{L}$ vs 103.9 [91.5-118.0] $\mu \mathrm{mol} / \mathrm{L})$ at admission (Supplementary Table 1).

\section{Treatment and clinical outcomes}

In this cohort, patients with hypertension vs those without hypertension had a similar durations from symptom onset to admission (median [IQR], 11 [8-15] days vs 10 [7-13] days; $\mathrm{P}=0.102)$. Compared with those without hypertension, patients with hypertension required more noninvasive ventilation (23 [32.9\%] vs 25 [16.7\%]; $\mathrm{P}=0.007)$ and invasive mechanical ventilation (13 [18.6\%] vs 13 [8.7\%]; $\mathrm{P}=0.03)$. The use of antiviral treatment (63 [90.0\%] vs 142 [94.7\%]), antibiotic treatment (50 [71.4\%] vs 117 [78.0\%]), glucocorticoids (32 [43.7\%] vs 64 [42.7\%]), and intravenous immunoglobulin treatment (32 [51.6\%] vs 55 [48.2\%]) were similar between patients with hypertension and without hypertension (Table 2). Acute cardiac injury (22 [31.4\%] vs 10 [6.7\%]; $\mathrm{P}<0.001$ ), ARDS (18 [25.7\%] vs 13 [8.7\%]; P < 0.001) and acute kidney injury (12 [17.1\%] vs 7 [4.7\%]; $\mathrm{P}<0.001)$ were more common among patients with hypertension than those without hypertension (Table 2).

\section{Hypertension and in-hospital mortality}

There were 39 (17.7\%) patients died during hospitalization. The risk of in-hospital mortality was higher among patients with vs without hypertension (26 [37.1\%] vs 13 [8.7\%]; HR: 5.01; 95\%CI: 2.57-9.76, P < 0.001) (Figure 1). To detect potential confounders of inhospital mortality, we conducted univariate Cox proportional-hazards regression analysis. The results of univariate Cox proportional-hazards regression was shown in Supplementary Table 2. Then, multivariate Cox proportional-hazards regression analyzing was performed to evaluate the effect of baseline variables on mortality (Supplementary Table 3). After full adjusting for potential confounders in Model 1-5, the risk of inhospital mortality in patients with hypertension was still significantly higher than patients without hypertension (Figure 2).

\section{ACEI/ARB treatment in severe COVID-19 with hypertension}

Of the 70 patients with hypertension, 23 (32.9\%) patients received ACEI/ARB (ACEI: 8, ARB: 15) treatment and $47(67.7 \%)$ did not receive ACEI/ARB treatment. Eighteen of 21 patients taken ACEI/ARB before admission and continued during hospitalization, and 2 patients administrated ARB at admission. Most of patients (38 [80.9\%]) taken calcium channel blockers in control group. As presented in Supplementary Table 4, there were no significant differences in age, sex, preexisting diseases, signs and symptoms, and blood pressure level between the with ACEI/ARB group and without ACEI/ARB group. However, patients with 
Table 1. Baseline characteristics of patients infected with severe COVID-19.

\begin{tabular}{|c|c|c|c|c|}
\hline Characteristics & All patients $(n=220)$ & Hypertension $(n=70)$ & Control $(n=150)$ & $P$ trend \\
\hline Age, years & $59.5(48.3-70.0)$ & $68.5(60.8-77.0)$ & $54.5(41.0-65.3)$ & $<0.001$ \\
\hline$<60$ & $110(50)$ & $16(22.9)$ & $94(62.7)$ & \\
\hline$\geq 60,<75$ & $69(31.4)$ & $31(44.3)$ & $38(25.3)$ & \\
\hline$\geq 75$ & $41(18.6)$ & $23(32.8)$ & $18(12.0)$ & \\
\hline \multicolumn{5}{|l|}{ Sex } \\
\hline Male & $106(48.2)$ & $38(54.3)$ & $68(45.3)$ & 0.132 \\
\hline Female & $114(51.8)$ & $32(45.7)$ & $82(54.7)$ & \\
\hline CAD & $22(10.0)$ & $16(22.9)$ & $6(4.0)$ & $<0.001$ \\
\hline Diabetes mellitus & $34(15.5)$ & $14(20.0)$ & $20(13.3)$ & 0.203 \\
\hline CVD & $8(4.5)$ & $4(6.5)$ & $4(3.5)$ & 0.371 \\
\hline COPD & $8(3.6)$ & $3(4.3)$ & $5(3.3)$ & 0.770 \\
\hline Malignancy & $4(1.8)$ & $2(2.9)$ & $2(1.3)$ & 0.431 \\
\hline Chronic liver disease & $7(3.2)$ & $1(1.4)$ & $6(4.0)$ & 0.312 \\
\hline \multicolumn{5}{|l|}{ Signs and symptoms } \\
\hline Fever & $173(78.6)$ & $56(80.0)$ & $117(78.0)$ & 0.599 \\
\hline Fatigue & 85 (38.6) & $30(42.9)$ & $55(36.7)$ & 0.380 \\
\hline Cough & $146(66.4)$ & $44(62.9)$ & $102(68.0)$ & 0.452 \\
\hline Myalgia & $22(10.0)$ & $5(7.1)$ & $17(11.3)$ & 0.335 \\
\hline Dyspnea & $94(42.7)$ & $38(54.3)$ & $56(37.3)$ & 0.018 \\
\hline Pharyngalgia & $158.5)$ & $2(3.2)$ & $13(11.4)$ & 0.064 \\
\hline Diarrhea & $28(12.7)$ & $10(14.3)$ & $18(12.0)$ & 0.636 \\
\hline Nausea or vomiting & $25(11.4)$ & $7(10.0)$ & $18(12.0)$ & 0.688 \\
\hline Headache & $11(5.0)$ & $3(4.3)$ & $8(5.3)$ & 0.740 \\
\hline Temperature, IQR & $36.7(36.5-37.1)$ & $36.8(36.5-37.6)$ & $36.7(36.5-37.0)$ & 0.476 \\
\hline HR, bpm, IQR & $85(78-95)$ & $84(77-94)$ & $86(78-97)$ & 0.568 \\
\hline Respiratory rate, IQR & $20(19-22)$ & $20(19-25)$ & $20(19-21)$ & 0.344 \\
\hline SBP (mmHg), IQR & $125(115-135)$ & $130(122-144)$ & $121(115-131)$ & 0.001 \\
\hline DBP (mmHg), IQR & $78(70-82)$ & $79(70-88)$ & $77(70-81)$ & 0.080 \\
\hline
\end{tabular}

ACE/ARB: Angiotensin-converting enzyme inhibitors/angiotensin receptor blockers, CAD: Coronary artery disease, CDOP: Chronic obstructive pulmonary disease, CVD: Cerebrovascular disease, DBP: Diastolic blood pressure, SBP: Systolic blood pressure, IQR: interquartile range, HR: Heart rate.

ACEI/ARB treatment compared with patients without ACEI/ARB treatment showed lower median hs-cTnI (median [IQR], 12 [0-54] pg/mL vs $21[0-170] \mathrm{pg} / \mathrm{mL}$ ) and CK-MB (median [IQR], 1.52 [0.81-2.40] ng/ml vs $2.31[1.23-4.00)] \mathrm{ng} / \mathrm{ml})$ (Supplementary Table 5).

As shown in Table 3, patients treated with ACEI/ARB vs those treated without ACEI/ARB had similar durations from symptom onset to admission (median
[IQR], 11 [9-14] days vs 10 [7-15] days; $\mathrm{P}=0.893$ ) and treatments (antiviral, antibiotics, glucocorticoid, immunoglobulin and noninvasive or invasive ventilation). Although there was no statistical difference, ACEI/ARB use was associated with a trend for reducing the risk of acute heart injury (4 [17.4\%] vs 18 [38.3\%]; $\mathrm{P}=0.078$ ). No significant differences were observed in the risk of ARDS (6 [26.1] vs 12 [25.5\%]; P $=0.960)$, acute kidney injury (2 [8.7\%] vs 10 [21.3\%]; 
Table 2. Treatments and clinical outcomes in patients with severe COVID-19.

\begin{tabular}{lcccc}
\hline Treatments and outcomes & $\begin{array}{c}\text { All patients } \\
(\mathbf{n = 2 2 0})\end{array}$ & $\begin{array}{c}\text { Hypertension } \\
(\mathbf{n = 7 0})\end{array}$ & $\begin{array}{c}\text { Control } \\
(\mathbf{n}=\mathbf{1 5 0})\end{array}$ & P trend \\
\hline Treatment & & & & \\
Onset of symptom to hospital admission, IQR & $10(7-14)$ & $11(8-15)$ & $10(7-13)$ & 0.102 \\
Antiviral treatment & $205(93.2)$ & $63(90.0)$ & $142(94.7)$ & 0.201 \\
Antibiotics & $167(75.9)$ & $50(71.4)$ & $117(78)$ & 0.288 \\
Glucocorticoid therapy & $96(43.6)$ & $32(45.7)$ & $64(42.7)$ & 0.671 \\
Immunoglobulin therapy & $87(49.3)$ & $32(51.6)$ & $55(48.2)$ & 0.201 \\
Oxygen inhalation & $190(86.4)$ & $67(95.7)$ & $123(82.0)$ & 0.006 \\
NIV & $48(21.8)$ & $23(32.9)$ & $25(16.7)$ & 0.007 \\
IMV & $26(11.8)$ & $13(18.6)$ & $13(8.7)$ & 0.030 \\
Outcome & & & & $<0.7$ \\
Acute cardiac injury & $32(14.5)$ & $22(31.4)$ & $10(6.7)$ & $<0.001$ \\
ARDS & $31(14.1)$ & $18(25.7)$ & $13(8.7)$ & $<0.001$ \\
Acute kidney injury & $19(8.6)$ & $12(17.1)$ & $7(4.7)$ & $<0.001$ \\
In-hospital mortality & $39(17.7)$ & $26(37.1)$ & $13(8.7)$ & $<0.001$ \\
\hline
\end{tabular}

ARDS: Acute respiratory distress syndrome; NIV: Noninvasive ventilation; IMV: Invasive mechanical ventilation; IQR: Interquartile range.

$\mathrm{P}=0.190)$ and in-hospital mortality $(6[26.1 \%]$ vs 20 [42.6\%]; $\mathrm{P}=0.181$ ) between the two groups.

\section{DISCUSSION}

The major findings of our study are the following: (i) hypertension is highly prevalent among patients with severe COVID-19; (ii) patients with hypertension were more likely to suffer from severe inflammatory and acute cardiac injury; (iii) hypertension is an independent risk factor of in-hospital mortality; (iv) the use of ACEI/ARB may protect COVID-19 from acute cardiac injury.

Several epidemiological studies have reported that hypertension is one of the most distinctive comorbidities in patients with severe COVID-19 (approximately 23-56.6\%) [4-5, 11]. Consistent with these studies, our data showed that $31.8 \%$ patients with severe COVID-19 had a history of hypertension.

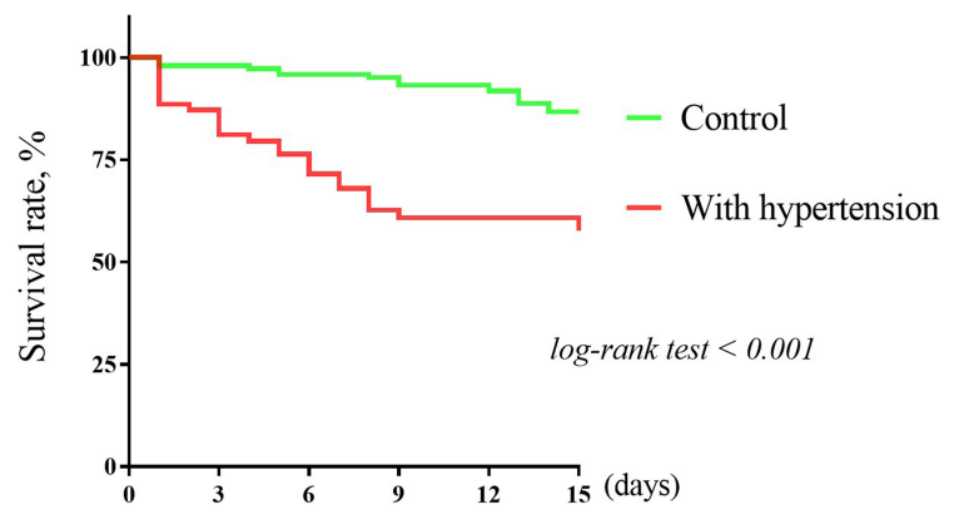

Length of stay

Figure 1. The Kaplan-Meier survival curves for hypertension and in-hospital mortality. 
Patients with severe COVID-19 with hypertension seemed to be older and have more comorbidities than those without hypertension. In this study, we found that patients with hypertension were more likely to suffer from acute cardiac injury.

It might be explained by the reason that the proportion of patients with coronary artery disease in hypertension was higher than patients without hypertension, and more potential cardiac dysfunction might preexist in patients with hypertension, such as left ventricular hypertrophy and heart failure. This may also be one of the reasons why dyspnea was more common in patients with hypertension. Recently, some studies reported that cardiac injury was a frequent condition among hospitalized patients with COVID-19, and it was associated with a higher risk of in-hospital mortality [12].

We have also observed that patients with hypertension suffered from more severe inflammation than cases without hypertension. The expression of ACE2 is relatively insufficient in hypertension. Persistent severe acute respiratory syndrome coronavirus (SARS-CoV-2) infection and replication contribute to reduced ACE2 expression [13-14]. The down-regulation of ACE2 activity in the organs promotes the initial leukocytes infiltration, which contributes to the extent of inflammation after viral infection [15]. In addition, the accelerated ageing of the immune system in hypertension may be another reason why hypertensive patients are potentially related to a more severe inflammation in COVID-19 [16].

Although hypertension has become a major comorbidity in patients with COVID-19, it is unclear whether hypertension is directly related to an increased risk of fatal outcomes. In our study, we found that hypertension was associated with a significantly high risk of in-hospital mortality. Hypertension plays a key role in the development of chronic target organ damage (mainly heart and kidney) and may be exacerbated after SARS-CoV-2 infection, just like other infections. These conditions may lead to higher hospital mortality.

Even if the HR value was weakened after adjustment for multiple potential confounders, including sex, age, cardiac injury, inflammation makers and emerging risk factors of renal dysfunction and D-dimer [17-18], hypertension is still an independent risk factor of inhospital mortality. In addition, we found that the risk of ARDS in hypertensive patients was significantly higher than that in non- hypertensive patients. The aggravated inflammation in hypertension may contribute to the increased risk of ARDS.

A previous study reported that ACEI/ARB chronic therapy, through their beneficial effects on the cardiovascular system, had a positive effect on survival in very elderly hospitalized patients [19]. Although there are few reports in humans regarding

\section{Hypertension vs Control}

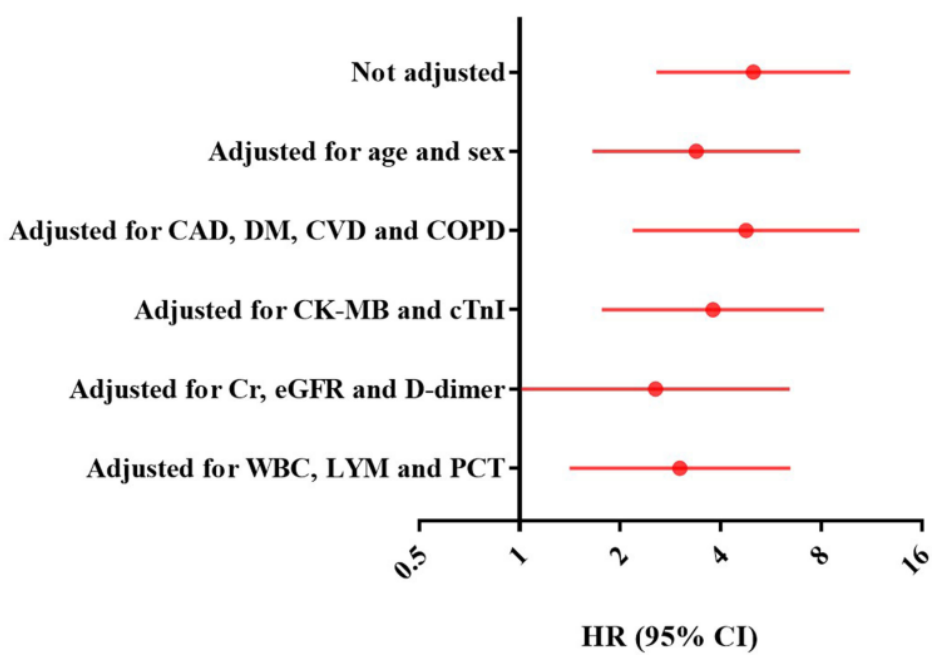

Figure 2. Forest plots of multivariate Cox proportional-hazards regression analyzing the effect of baseline variables on mortality. CAD: Coronary artery disease, $\mathrm{Cl}$ : Confidence interval; CK-MB: Creatinine kinase-myocardial band; COPD: Chronic obstructive pulmonary disease; CVD: Cerebrovascular disease; DM: Diabetes mellitus; eGFR: Estimated glomerular filtration rate; HTN: hypertension; HR: Hazards ratio; hs-cTnl: High-sensitivity cardiac troponin I; LYM: Lymphocytes; PCT: Procalcitonin; Cr: Creatinine, WBC: White blood cell. 
Table 3. Treatments and clinical outcomes in severe COVID-19 with hypertension.

\begin{tabular}{lccc}
\hline Treatments and outcomes & ACEI/ARB(n = 23) & no ACEI/ARB (n = 47) & P trend \\
\hline Treatment & & & \\
Onset of symptom to hospital admission, IQR & $11(9-14)$ & $10(7-15)$ & 0.893 \\
Antiviral treatment & $21(91.3)$ & $42(89.4)$ & 0.799 \\
Antibiotics & $16(69.6)$ & $34(72.3)$ & 0.809 \\
Glucocorticoid therapy & $13(56.5)$ & $19(40.4)$ & 0.072 \\
Immunoglobulin therapy & $13(65.0)$ & $19(45.2)$ & 0.146 \\
Oxygen inhalation & $22(95.6)$ & $43(91.5)$ & 0.985 \\
NIV & $8(34.8)$ & $15(31.9)$ & 0.810 \\
IMV & $5(21.7)$ & $8(17.0)$ & 0.634 \\
Outcome & & & \\
Acute cardiac injury & $4(17.4)$ & $18(38.3)$ & 0.078 \\
ARDS & $6(26.1)$ & $12(25.5)$ & 0.960 \\
Acute kidney injury & $2(8.7)$ & $10(21.3)$ & 0.190 \\
In-hospital mortality & $6(26.1)$ & $20(42.6)$ & 0.181 \\
\hline
\end{tabular}

ACEI/ARB: Angiotensin-converting enzyme inhibitors/angiotensin receptor blockers; ARDS: Acute respiratory distress syndrome; NIV: Noninvasive ventilation; IMV: Invasive mechanical ventilation; IQR: Interquartile range.

the effects of ACEI/ARB on ACE2 expression [20, 21], experimental evidence has supported that the expression of ACE2 is substantially up-regulation by administering ACEI/ARB [22]. Based on this effect, the use of ACEI/ARB has been proved to be effective in reducing lung injury in animal models of ARDS [23]. However, it has been confirmed that SARSCoV-2 uses the ACE2 receptor as an entry point into the host cell [24]. Therefore, the use of ACEI/ARB in COVID-19 with hypertension were controversial.

Fang et al suggested that hypertension with ACE2stimulating drugs was associated with an increased risk of developing severe and fatal COVID-19 [9]. But several recent studies have reported that the use of ACEI/ARB has nothing to do with the increased risk of fatal consequences of COVID-19 combined with hypertension [4, 25, 26]. In agreement with these studies, we also found that the use of ACEI/ARB did not have adverse effect on signs, symptoms and clinical outcomes in severe COVID-19. Interestingly, we found that the ACEI/ARB treatment was associated with lower level of hs-cTnI, CK-MB and a lower risk of acute cardiac injury, which indicated that ACEI/ARB use might help to alleviate cardiac injury of severe COVID-19. The benefits of ACEI/ARB on cardiovascular diseases may help reduce the risk of acute cardiac injury $[19,27]$.

This study has several limitations that must be acknowledged. First, as the data on echocardiography was waived in light of the urgent medical condition, the underlying cardiac function of severe COVID-19 cases was unclear. We could not entirely rule out the possibility of residual confounders by these unmeasured parameters. Second, data were extracted from a preexisting electronic medical records, which subjects it to potential selection bias. But it could be minimized by conducting multivariate regression analyses. Third, for the effect of ACEI/ARB on severe COVID-19 with hypertension, the sample size of this study was small and our findings still need to be further confirmed.

In summary, patients with COVID-19 with hypertension was more likely to suffer from severe cardiac injury, inflammatory response and poor prognosis. Considering the high risk of death, incremental caution and in-hospital discussion of anticipated risk in hypertension are completely necessary. In addition, administration of ACEI/ARB may contribute to low risk of acute cardiac injury in severe COVID-19. Our findings supported that ACEI/ARB can continue to be used in patients with severe COVID-19.

\section{MATERIALS AND METHODS}

\section{Study design and participants}

This was a retrospective, observational study registry with https://clinicaltrials.gov/ identifier NCT04292964. Consecutive patients with severe COVID-19 admitted to hospitals in Hubei and Chongqing from January 11st, 2020 to February 20th, 2020, were collected by national medical team. Case definitions of confirmed human 
infection with COVID-19 conformed to the interim guidance from the World Health Organization. All patients were diagnosed as severe cases according to the 7th edition guideline issued by China's National Health Commission. This study was approved by the institutional ethics board of the First Affiliated Hospital of Chongqing Medical University (approval NO. 20200701). The study was also registered on Chinese medical research registration information system.

\section{Data collections}

Information on symptoms, signs, underlying comorbidities, laboratory findings, blood pressure, medical history (i.e. ACEI, ARB and calcium channel blocker), treatments and clinical outcomes were obtained from electronic medical records. All the data were collected by two investigators independently and double checked by other investigators. If the information on medical history were not available from electronic medical records, we directly communicated with patients or their families to obtain further data.

\section{Definition and study outcome}

Severe COVID-19 was defined as meeting at least one of the following criteria: 1 ) respiratory rate $\geq 30 / \mathrm{min} ; 2$ ) at rest, oxygen saturation $\left(\mathrm{SpO}_{2}\right)$ is $\left.\leq 93 \% ; 3\right)$ partial pressure of oxygen $\left(\mathrm{PaO}_{2}\right)$ /Fraction of inspiration $\mathrm{O}_{2}$ $\left(\mathrm{FiO}_{2}\right) \leq 300 \mathrm{mmHg}$. ACEI/ARB treatment was defined as a patient taking ACEI/ARB during hospitalization irrespective of dose and whether taken before admission or not. The primary endpoint was in-hospital mortality, defined as any death occurring within 15 days after hospitalization. The secondary endpoints included acute cardiac injury, ARDS and acute kidney injury. Acute cardiac injury was defined as blood levels of cardiac biomarkers (hs-cTnI) above the 99th-percentile upper reference limit.

\section{Statistical analysis}

Continuous measurements described as mean (standard deviation: [SD]) if they are normally distributed or median (interquartile range: [IQR)] if they are not. Categorical variables were described as frequency rates and percentages. Test for differences in categorical variables among the two groups used $\mathrm{X}^{2}$ test. T test or Mann-Whitney test was used to compare continuous variables according to the normal distribution or not. The Kaplan-Meier product-limit estimation method was used to estimate survival rates, and the statistical differences were compared using log-rank tests. The univariate and multivariate Cox proportional hazard model was used to estimate the hazard ratios (HRs) and 95\% confidence intervals (CIs). All $\mathrm{P}$ values were two-tailed, and significance was set at $\mathrm{P}<0.05$. Statistical analyses were performed using SPSS software (version 22.0).

\section{AUTHOR CONTRIBUTIONS}

Dongying Zhang, Jianzhong Zhou and Shu Qin contributed to the design of study. Xiaocheng Cheng, Jianzhong Zhou and Dongying Zhang were responsible for editing and revising manuscript. Xiaocheng Cheng, Guoqiang Cai, Xuesong Wen, Lei Gao, Dan Jiang and Min Sun collected data. Xiaocheng Cheng and Guoqiang Cai performed data analysis. Xiaocheng Cheng and Dongying Zhang written the manuscript. All authors approved the final version of the article.

\section{ACKNOWLEDGMENTS}

We thank all the staffs working at the front-line to battle against COVID-19. We show our respect to those who have sacrificed in this war.

\section{CONFLICTS OF INTEREST}

The authors declare that they have no conflicts of interest.

\section{FUNDING}

This study was supported by National Natural Science Foundation of China, 81970203; National Natural Science Foundation of China, 81570212; National Natural Science Foundation of China, 31800976; Chongqing Science and Health Joint Medical Research Project, 2018QNXM024.

\section{REFERENCES}

1. Li Q, Guan X, Wu P, Wang X, Zhou L, Tong $Y$, Ren R, Leung KS, Lau EH, Wong JY, Xing X, Xiang N, Wu Y, et al. Early transmission dynamics in Wuhan, China, of novel coronavirus-infected pneumonia. N Engl J Med. 2020; 382:1199-207.

https://doi.org/10.1056/NEJMoa2001316

PMID:31995857

2. Chen N, Zhou M, Dong X, Qu J, Gong F, Han Y, Qiu Y, Wang J, Liu Y, Wei Y, Xia J, Yu T, Zhang X, Zhang L. Epidemiological and clinical characteristics of 99 cases of 2019 novel coronavirus pneumonia in Wuhan, China: a descriptive study. Lancet. 2020; 395:507-13.

https://doi.org/10.1016/S0140-6736(20)30211-7 PMID: $\underline{32007143}$

3. $X u X W, W u X X$, Jiang $X G, X u K J$, Ying $L J, M a C L$, Li $S B$, Wang HY, Zhang S, Gao HN, Sheng JF, Cai HL, Qiu YQ, Li $\mathrm{L}$. Clinical findings in a group of patients infected with 
the 2019 novel coronavirus (SARS-Cov-2) outside of Wuhan, China: retrospective case series. BMJ. 2020; 368:m606.

https://doi.org/10.1136/bmj.m606

PMID:32075786

4. Richardson S, Hirsch JS, Narasimhan M, Crawford JM, McGinn T, Davidson KW, Barnaby DP, Becker LB, Chelico JD, Cohen SL, Cookingham J, Coppa K, Diefenbach MA, et al, and the Northwell COVID-19 Research Consortium. Presenting characteristics, comorbidities, and outcomes among 5700 patients hospitalized with COVID-19 in the New York city area. JAMA. 2020; 323:2052-59.

https://doi.org/10.1001/jama.2020.6775

PMID:32320003

5. Guan WJ, Ni ZY, Hu Y, Liang WH, Ou CQ, He JX, Liu L, Shan $\mathrm{H}$, Lei $\mathrm{CL}$, Hui DS, Du B, Li L, Zeng G, et al, and China Medical Treatment Expert Group for Covid-19. Clinical characteristics of coronavirus disease 2019 in China. N Engl J Med. 2020; 382:1708-20.

https://doi.org/10.1056/NEJMoa2002032

PMID:32109013

6. Whelton PK, Carey RM, Aronow WS, Casey DE Jr, Collins KJ, Dennison Himmelfarb C, DePalma SM, Gidding S, Jamerson KA, Jones DW, MacLaughlin EJ, Muntner P, Ovbiagele B, et al. 2017 ACC/AHA/AAPA/ABC/ACPM/AGS/APhA/ASH/ASPC/N MA/PCNA Guideline for the Prevention, Detection, Evaluation, and Management of High Blood Pressure in Adults: A Report of the American College of Cardiology/American Heart Association Task Force on Clinical Practice Guidelines. Hypertension. 2018; 71:e13-e115.

https://doi.org/10.1161/HYP.0000000000000065 PMID:29133356

7. Williams B, Mancia G, Spiering W, Agabiti Rosei E, Azizi M, Burnier M, Clement DL, Coca A, de Simone G, Dominiczak A, Kahan T, Mahfoud F, Redon J, et al, and ESC Scientific Document Group. 2018 ESC/ESH guidelines for the management of arterial hypertension. Eur Heart J. 2018; 39:3021-104. https://doi.org/10.1093/eurhearti/ehy339 PMID:30165516

8. Sommerstein R, Gra"ni C. Rapid response: re: preventing a covid-19 pandemic: ACE inhibitors as a potential risk factor for fatal Covid-19. BMJ. 2020. https://www.bmj.com/content/368/bmj.m810/rr-2

9. Fang L, Karakiulakis G, Roth M. Are patients with hypertension and diabetes mellitus at increased risk for COVID-19 infection? Lancet Respir Med. 2020; 8:e21.

https://doi.org/10.1016/S2213-2600(20)30116-8 PMID:32171062
10. Kuster GM, Pfister O, Burkard T, Zhou Q, Twerenbold $R$, Haaf P, Widmer AF, Osswald S. SARS-CoV2: should inhibitors of the renin-angiotensin system be withdrawn in patients with COVID-19? Eur Heart J. 2020; 41:1801-03.

https://doi.org/10.1093/eurhearti/ehaa235 PMID: $\underline{2196087}$

11. Huang $C$, Wang $Y$, Li $X$, Ren $L$, Zhao J, Hu Y, Zhang L, Fan G, Xu J, Gu X, Cheng Z, Yu T, Xia J, et al. Clinical features of patients infected with 2019 novel coronavirus in Wuhan, China. Lancet. 2020; 395:497-506. https://doi.org/10.1016/S0140-6736(20)30183-5 PMID:31986264

12. Shi S, Qin M, Shen B, Cai Y, Liu T, Yang F, Gong W, Liu X, Liang J, Zhao $Q$, Huang $H$, Yang B, Huang C. Association of cardiac injury with mortality in hospitalized patients with COVID-19 in Wuhan, China. JAMA Cardiol. 2020; 5:802-10.

https://doi.org/10.1001/jamacardio.2020.0950 PMID: $\underline{2211816}$

13. Wan Y, Shang J, Graham R, Baric RS, Li F. Receptor recognition by the novel coronavirus from Wuhan: an analysis based on decade-long structural studies of SARS coronavirus. J Virol. 2020; 94:e00127-20. https://doi.org/10.1128/JVI.00127-20 PMID:31996437

14. Lan J, Ge J, Yu J, Shan S, Zhou H, Fan S, Zhang Q, Shi X, Wang $Q$, Zhang L, Wang $X$. Structure of the SARS-CoV-2 spike receptor-binding domain bound to the ACE2 receptor. Nature. 2020; 581:215-20. https://doi.org/10.1038/s41586-020-2180-5 PMID:32225176

15. Imai Y, Kuba K, Rao S, Huan Y, Guo F, Guan B, Yang P, Sarao R, Wada T, Leong-Poi $H$, Crackower MA, Fukamizu A, Hui CC, et al. Angiotensin-converting enzyme 2 protects from severe acute lung failure. Nature. 2005; 436:112-16. https://doi.org/10.1038/nature03712 PMID:16001071

16. Youn JC, Yu HT, Lim BJ, Koh MJ, Lee J, Chang DY, Choi YS, Lee SH, Kang SM, Jang Y, Yoo OJ, Shin EC, Park S. Immunosenescent CD8+ T cells and C-X-C chemokine receptor type 3 chemokines are increased in human hypertension. Hypertension. 2013; 62:126-33. https://doi.org/10.1161/HYPERTENSIONAHA.113.00689 5

17. Zhou F, Yu T, Du R, Fan G, Liu Y, Liu Z, Xiang J, Wang Y, Song B, Gu X, Guan L, Wei Y, Li H, et al. Clinical course and risk factors for mortality of adult inpatients with COVID-19 in Wuhan, China: a retrospective cohort study. Lancet. 2020; 395:1054-62. https://doi.org/10.1016/S0140-6736(20)30566-3 PMID:32171076

18. Pan XW, Xu D, Zhang H, Zhou W, Wang LH, Cui XG. 
Identification of a potential mechanism of acute kidney injury during the COVID-19 outbreak: a study based on single-cell transcriptome analysis. Intensive Care Med. 2020; 46:1114-16.

https://doi.org/10.1007/s00134-020-06026-1

PMID:32236644

19. Spannella F, Giulietti F, Balietti P, Cocci G, Landi L, Lombardi FE, Borioni E, Bernardi B, Rosettani G, Bordoni V, Sarzani R. Renin-angiotensin system blockers and statins are associated with lower inhospital mortality in very elderly hypertensives. J Am Med Dir Assoc. 2018; 19:342-47.

https://doi.org/10.1016/i.jamda.2017.09.023

PMID:29128438

20. Vaduganathan M, Vardeny $\mathrm{O}$, Michel T, McMurray JJ, Pfeffer MA, Solomon SD. Renin-angiotensinaldosterone system inhibitors in patients with covid19. N Engl J Med. 2020; 382:1653-59. https://doi.org/10.1056/NEJMsr2005760 PMID: $\underline{32227760}$

21. Danser AH, Epstein M, Batlle D. Renin-angiotensin system blockers and the COVID-19 pandemic: at present there is no evidence to abandon reninangiotensin system blockers. Hypertension. 2020; 75:1382-85.

https://doi.org/10.1161/HYPERTENSIONAHA.120.15082 PMID:32208987

22. Ferrario CM, Jessup J, Chappell MC, Averill DB, Brosnihan KB, Tallant EA, Diz DI, Gallagher PE. Effect of angiotensin-converting enzyme inhibition and angiotensin II receptor blockers on cardiac angiotensinconverting enzyme 2. Circulation. 2005; 111:2605-10. https://doi.org/10.1161/CIRCULATIONAHA.104.510461 PMID:15897343

23. Sarzani R, Giulietti F, Pentima CD, Giordano P, Spannella F. Severe acute respiratory syndrome coronavirus 2 infection, angiotensin-converting enzyme 2 and treatment with angiotensin-converting enzyme inhibitors or angiotensin II type 1 receptor blockers. Eur J Prev Cardiol. 2020. [Epub ahead of print]. https://doi.org/10.1177/2047487320918421 PMID:32290680

24. Wu Y, Wang F, Shen C, Peng W, Li D, Zhao C, Li Z, Li S, Bi Y, Yang $Y$, Gong $Y$, Xiao $H$, Fan $Z$, et al. A noncompeting pair of human neutralizing antibodies block COVID-19 virus binding to its receptor ACE2. Science. 2020; 368:1274-78.

https://doi.org/10.1126/science.abc2241 PMID:32404477

25. Li J, Wang X, Chen J, Zhang H, Deng A. Association of renin-angiotensin system inhibitors with severity or risk of death in patients with hypertension hospitalized for coronavirus disease 2019 (COVID-19) infection in Wuhan, China. JAMA Cardiol. 2020; 5:825-30.

https://doi.org/10.1001/jamacardio.2020.1624 PMID:32324209

26. Zhang $P$, Zhu L, Cai J, Lei F, Qin JJ, Xie J, Liu YM, Zhao YC, Huang $X$, Lin L, Xia $M$, Chen MM, Cheng $X$, et al. Association of Inpatient Use of AngiotensinConverting Enzyme Inhibitors and Angiotensin II Receptor Blockers With Mortality Among Patients With Hypertension Hospitalized With COVID-19. Circ Res. 2020; 126:1671-81.

https://doi.org/10.1161/CIRCRESAHA.120.317134 PMID:32302265

27. Brojakowska A, Narula J, Shimony R, Bander J. Clinical implications of SARS-CoV-2 interaction with renin angiotensin system: JACC review topic of the week. J Am Coll Cardiol. 2020; 75:3085-95. https://doi.org/10.1016/i.jacc.2020.04.028 PMID:32305401 


\section{SUPPLEMENTARY MATERIALS}

\section{Supplementary Tables}

Supplementary Table 1. Laboratory findings of patients infected with severe COVID-19 at admission.

\begin{tabular}{|c|c|c|c|c|c|}
\hline Variables, IQR or \% & Normal Range & $\begin{array}{l}\text { All patients } \\
(\mathbf{n}=\mathbf{2 2 0})\end{array}$ & $\begin{array}{l}\text { Hypertension } \\
\quad(\mathbf{n}=\mathbf{7 0})\end{array}$ & $\begin{array}{c}\text { Control } \\
(\mathbf{n}=150)\end{array}$ & $P$ trend \\
\hline hs-cTnI, pg/mL & $0-40$ & $4(0-19)$ & $17(0-71)$ & $0(0-9)$ & $<0.001$ \\
\hline $\mathrm{CK}-\mathrm{MB}, \mathrm{ng} / \mathrm{mL}$ & $0-5$ & $1.14(0.67-2.69)$ & $2.04(1.02-3.61)$ & $0.95(0.60-2.12)$ & $<0.001$ \\
\hline NT-proBNP, pg/mL & $>90$ & $220.4(52.3-867.1)$ & $537.8(172.6-1340.5)$ & $120.2(36.7-391.9)$ & $<0.001$ \\
\hline Total cholesterol, mmol/L & $0-5.2$ & $3.70(3.29-4.33)$ & $3.85(3.34-4.26)$ & $3.66(3.28-4.48)$ & 0.987 \\
\hline LDL cholesterol, mmol/L & $0-3.4$ & $2.4(1.9-2.9)$ & $2.40(1.87-2.45)$ & $2.24(1.85-2.81)$ & 0.623 \\
\hline HDL cholesterol, mmol/L & $>1.00$ & $0.90(0.76-1.06)$ & $0.88(0.74-1.00)$ & $0.92(0.78-1.06)$ & 0.282 \\
\hline Triglycerides, mmol/L & $0-1.7$ & $1.27(0.99-1.80)$ & $1.19(0.99-1.60)$ & $1.33(0.96-1.99)$ & 0.370 \\
\hline WBC count, $\times 10^{9} / \mathrm{L}$ & $3.5-9.5$ & $5.45(4.10-7.05)$ & $6.26(4.44-8.20)$ & $5.17(3.95-6.70)$ & 0.003 \\
\hline Neutrophil count, $\times 10^{9} / \mathrm{L}$ & $1.8-6.3$ & $3.74(2.58-5.49)$ & $4.48(2.84-6.77)$ & $3.33(2.41-4.89)$ & 0.002 \\
\hline hs-CRP, mg/L & $0-3$ & $39.80(5.83-87.50)$ & $56.50(15.50-128.60)$ & $25.90(3.77-64.30)$ & $<0.001$ \\
\hline Procalcitonin, ng/mL & $0-1.0$ & $0.06(0.03-0.14)$ & $0.08(0.03-0.19)$ & $0.06(0.03-0.12)$ & 0.061 \\
\hline $\begin{array}{l}\text { Lymphocyte count, } \\
\times 10^{9} / \mathrm{L}\end{array}$ & $1.1-3.2$ & $1.02(0.71-1.43)$ & $0.92(0.55-1.43)$ & $1.05(0.75-1.43)$ & 0.193 \\
\hline Monocyte count, $\%$ & $3--10$ & $8.20(5.20-10.45)$ & $7.00(3.40-9.50)$ & $8.45(5.93-10.70)$ & 0.044 \\
\hline Platelet count, $\times 10^{9} / \mathrm{L}$ & $125-350$ & $198(147-261)$ & $199(139-278)$ & $197(147-260)$ & 0.726 \\
\hline Prothrombin time, s & 9--13 & $11.90(11.30-12.60)$ & $12.30(11.60-12.90)$ & $11.50(11.13-12.50)$ & $<0.001$ \\
\hline APTT, s & $25-31.3$ & $27.90(25.80-31.25)$ & $27.70(25.80-30.90)$ & $27.90(25.75-31.28)$ & 0.996 \\
\hline D-dimer, mg/L & $0-0.55$ & $0.80(0.40-3.80)$ & $1.83(0.56-8.90)$ & $0.61(0.36-1.98)$ & $<0.001$ \\
\hline ALT, U/L & $7-40$ & $26(16-42)$ & $25(17-50)$ & $27(16-40)$ & 0.398 \\
\hline $\mathrm{AST}, \mathrm{U} / \mathrm{L}$ & $13-35$ & $30(20-43)$ & $32(21-50)$ & $28(20-41)$ & 0.036 \\
\hline Total bilirubin, $\mathrm{mmol} / \mathrm{L}$ & $0-23$ & $10.30(7.50-15.45)$ & $10.35(7.25-16.20)$ & $10.10(7.50-15.20)$ & 0.804 \\
\hline $\begin{array}{l}\text { Blood urea nitrogen, } \\
\mathrm{mmol} / \mathrm{L}\end{array}$ & $3.1-8.8$ & $4.70(3.53-6.47)$ & $5.73(4.15-9.30)$ & $4.36(3.39-5.53)$ & $<0.001$ \\
\hline Creatinine, $\mu \mathrm{mol} / \mathrm{L}$ & $41-81$ & $61(49-75)$ & $69(51-84)$ & $59(49-72)$ & 0.023 \\
\hline eGFR & $>90$ & $98.8(82.0-109.5)$ & $89.3(57.3-99.1)$ & $103.9(91.5-118.0)$ & $<0.001$ \\
\hline $\begin{array}{l}\text { Bilateral distribution of } \\
\text { patchy shadows or } \\
\text { ground glass opacity }\end{array}$ & - & $215(97.7)$ & $69(98.6)$ & $148(98.7)$ & 0.955 \\
\hline
\end{tabular}

ALT: Alanine aminotransferase; AST: Aspartate aminotransferase, APTT: Activated partial thromboplastin time, CK-MB: creatinine kinase-myocardial band, eGFR: Estimated glomerular filtration rate, HDL: High density lipoprotein, hs-CRP: Highsensitivity C-reactive protein, hs-cTnl: high-sensitivity cardiac troponin I, IQR: interquartile range, LDL: Low density lipoprotein, NT-proBNP: N-terminal pro-B-type natriuretic peptide, WBC: White blood cell. 
Supplementary Table 2. Univariate Cox proportional-hazards regression analyzing the effect of baseline variables on in-hospital mortality.

\begin{tabular}{|c|c|c|c|}
\hline \multicolumn{2}{|l|}{ Characteristics } & HR (95\% CI) & P-value \\
\hline \multicolumn{4}{|l|}{ Sex } \\
\hline \multicolumn{2}{|l|}{ Male } & $2.11(1.09-4.05)$ & 0.026 \\
\hline \multicolumn{4}{|l|}{ Female } \\
\hline \multicolumn{2}{|l|}{ Age, $\geq 65$ years } & $4.20(2.09-8.44)$ & $<0.001$ \\
\hline \multirow[t]{2}{*}{ Hypertension } & Yes & $5.01(2.57-9.76)$ & $<0.001$ \\
\hline & No & & \\
\hline \multirow[t]{2}{*}{ History of DM } & Yes & $1.41(0.65-306)$ & 0.391 \\
\hline & No & & \\
\hline \multirow[t]{2}{*}{ History of CAD } & Yes & $2.55(1.17-5.55)$ & 0.019 \\
\hline & No & & \\
\hline \multirow[t]{2}{*}{ History of COPD } & Yes & $2.75(0.98-7.73)$ & 0.056 \\
\hline & No & & \\
\hline \multirow[t]{2}{*}{ History of CVD } & Yes & $3.75(1.31-10.71)$ & 0.013 \\
\hline & No & & \\
\hline \multicolumn{2}{|l|}{$\mathrm{CK}-\mathrm{MB},>5 \mathrm{ng} / \mathrm{ml}$} & $1.79(0.83-3.86)$ & 0.140 \\
\hline \multicolumn{2}{|l|}{ hs-cTnI, >1ng/ml } & $10.06(4.26-23.76)$ & $<0.001$ \\
\hline \multicolumn{2}{|l|}{ D-dimer, $>1 \mathrm{mg} / \mathrm{L}$} & $7.2(2.74-18.51)$ & $<0.001$ \\
\hline \multicolumn{2}{|c|}{ Creatinine, $>81 \mathrm{umol} / \mathrm{L}$} & $4.38(2.19-8.76)$ & $<0.001$ \\
\hline \multicolumn{2}{|c|}{$\mathrm{eGFR},<90 \mathrm{~mL} /\left(\min \cdot 1.73 \mathrm{~m}^{2}\right)$} & $4.66(2.21-9.80)$ & $<0.001$ \\
\hline \multicolumn{2}{|c|}{$\mathrm{WBC},>9.3 \times 10^{9} / \mathrm{L}$} & $6.12(3.11-12.06)$ & $<0.001$ \\
\hline \multicolumn{2}{|l|}{ LYM,$<1.1 \times 10^{9} / \mathrm{L}$} & $5.23(2.03-13.49)$ & 0.001 \\
\hline \multicolumn{2}{|l|}{$\mathrm{PCT},>1 \mathrm{ng} / \mathrm{ml}$} & $6.50(3.10-13.63)$ & $<0.001$ \\
\hline
\end{tabular}

CAD: Coronary artery disease; $\mathrm{Cl}$ : Confidence interval; CK-MB: Creatine kinase-MB; COPD: Chronic obstructive pulmonary disease; CVD: Cerebrovascular disease; DM: Diabetes mellitus; eGFR: Estimated glomerular filtration rate; HR: Hazards ratio; hs-cTnl: High-sensitivity cardiac troponin I; LYM: Lymphocytes; PCT: Procalcitonin; WBC: White blood cell. 
Supplementary Table 3. Multivariate Cox proportional-hazards regression analyzing the effect of baseline variables on in-hospital mortality.

\begin{tabular}{|c|c|c|}
\hline Mode & HR $(95 \% \mathrm{CI})$ & P-value \\
\hline Not Adjusted & $5.01(2.57-9.76)$ & $<0.001$ \\
\hline \multicolumn{3}{|l|}{ Mode 1} \\
\hline Hypertension & $3.38(1.65-6.92)$ & 0.001 \\
\hline Age $\geq 65$ years & $2.65(1.25-5.60)$ & 0.011 \\
\hline Male vs female & $2.00(1.04-3.86)$ & 0.038 \\
\hline \multicolumn{3}{|l|}{ Mode 2} \\
\hline Hypertension & $4.77(2.18-10.43)$ & $<0.001$ \\
\hline History of CVD & $2.30(0.75-7.03)$ & 0.144 \\
\hline History of CAD & $0.97(0.35-2.68)$ & 0.958 \\
\hline History of DM & $1.25(0.51-3.06)$ & 0.634 \\
\hline History of COPD & $3.98(0.97-16.32)$ & 0.055 \\
\hline \multicolumn{3}{|l|}{ Mode 3} \\
\hline Hypertension & $3.79(1.76-8.16)$ & 0.001 \\
\hline CK-MB, $>5 \mathrm{ng} / \mathrm{ml}$ & $1.64(0.75-3.58)$ & 0.235 \\
\hline hs-cTnI, >1ng/ml & $5.69(2.33-13.91)$ & $<0.001$ \\
\hline \multicolumn{3}{|l|}{ Mode 4} \\
\hline Hypertension & $2.55(1.01-6.45)$ & 0.048 \\
\hline D-dimer, $>1 \mathrm{mg} / \mathrm{L}$ & $3.81(1.43-10.18)$ & 0.008 \\
\hline Creatinine, $>100$ umol/L & $6.21(1.59-24.18)$ & 0.009 \\
\hline $\mathrm{eGFR},<60 \mathrm{~mL} /\left(\min \cdot 1.73 \mathrm{~m}^{2}\right)$ & $0.69(0.17-2.82)$ & 0.602 \\
\hline \multicolumn{3}{|l|}{ Mode 5} \\
\hline Hypertension & $3.02(1.41-6.47)$ & 0.005 \\
\hline $\mathrm{WBC},>9.3 \times 10^{9} / \mathrm{L}$ & $3.03(1.40-6.58)$ & 0.005 \\
\hline $\mathrm{LYM},<1.1 \times 10^{9} / \mathrm{L}$ & $3.24(1.20-8.77)$ & 0.020 \\
\hline $\mathrm{PCT},>1 \mathrm{ng} / \mathrm{ml}$ & $2.63(1.17-5.91)$ & 0.019 \\
\hline
\end{tabular}

CAD: Coronary artery disease; $\mathrm{Cl}$ : Confidence interval; CK-MB: Creatine kinase-MB; COPD: Chronic obstructive pulmonary disease; CVD: Cerebrovascular disease; DM: Diabetes mellitus; eGFR: Estimated glomerular filtration rate; HR: Hazards ratio; hs-cTnl: High-sensitivity cardiac troponin I; LYM: Lymphocytes; PCT: Procalcitonin; WBC: White blood cell. 
Supplementary Table 4. Baseline characteristics of hypertension infected with severe COVID-19.

\begin{tabular}{|c|c|c|c|}
\hline Variable & $\begin{array}{c}\text { ACEI/ARB } \\
(\mathbf{n}=\mathbf{2 3})\end{array}$ & $\begin{array}{c}\text { No ACEI/ARB } \\
(n=47) \\
\end{array}$ & P trend \\
\hline Age, y IQR & $69(59-75)$ & $68(62-78)$ & 0.417 \\
\hline$<60$ & $6(26.1)$ & $10(21.3)$ & \\
\hline$\geq 60,<75$ & $10(43.5)$ & $21(44.7)$ & \\
\hline$\geq 75$ & $7(30.4)$ & $16(34.0)$ & \\
\hline \multicolumn{4}{|l|}{ Sex } \\
\hline Male & $10(43.5)$ & $28(59.6)$ & 0.204 \\
\hline Female & $13(56.5)$ & $19(40.4)$ & \\
\hline CAD & $5(21.7)$ & $11(23.4)$ & 0.876 \\
\hline Diabetes mellitus & $4(17.4)$ & $12(25.5)$ & 0.446 \\
\hline CVD & $0(0)$ & $4(8.5)$ & 0.150 \\
\hline COPD & $1(4.3)$ & $2(4.3)$ & 0.986 \\
\hline Malignancy & $0(0)$ & $2(4.3)$ & 0.316 \\
\hline Chronic liver disease & $0(0)$ & $0(0)$ & $>0.99$ \\
\hline \multicolumn{4}{|l|}{ Signs and symptoms } \\
\hline Fever & $18(90.0)$ & $33(78.6)$ & 0.715 \\
\hline Temperature, IQR & $36.7(36.4-37.5)$ & $36.8(36.5-37.6)$ & 0.671 \\
\hline Fatigue & $9(45.0)$ & $15(38.1)$ & 0.483 \\
\hline Cough & $13(65.0)$ & $26(61.9)$ & 0.814 \\
\hline Myalgia & $1(5.0)$ & $2(4.8)$ & 0.967 \\
\hline Dyspnea & $9(45.0)$ & $22(52.4)$ & 0.587 \\
\hline Pharyngalgia & $1(5.0)$ & $1(2.4)$ & 0.585 \\
\hline Diarrhea & $3(15.0)$ & $4(9.5)$ & 0.524 \\
\hline Nausea or vomiting & $2(10.0)$ & $2(4.8)$ & 0.433 \\
\hline Headache & $1(5.0)$ & $2(4.8)$ & 0.967 \\
\hline HR, bpm, IQR & $84(76-92)$ & $85(78-95)$ & 0.508 \\
\hline Respiratory rate, IQR & $20(19-21)$ & $20(19-28)$ & 0.116 \\
\hline SBP (mmHg), IQR & $132(127-140)$ & $129(116-150)$ & 0.291 \\
\hline $\mathrm{DBP}(\mathrm{mmHg})$ & $78(70-85)$ & $80(69-90)$ & 0.501 \\
\hline
\end{tabular}

ACEI/ARB: Angiotensin-converting enzyme inhibitors/angiotensin receptor blockers, CAD: Coronary artery disease, CDOP: Chronic obstructive pulmonary disease, CVD: Cerebrovascular disease, DBP: Diastolic blood pressure, SBP: Systolic blood pressure, IQR: interquartile range, HR: Heart rate. 
Supplementary Table 5. Laboratory findings of hypertension infected with severe COVID-19 at admission.

\begin{tabular}{|c|c|c|c|}
\hline Variables, IQR or \% & $\begin{array}{l}\text { ACEI/ARB } \\
\quad(\mathbf{n}=\mathbf{2 3})\end{array}$ & $\begin{array}{c}\text { No ACE/ARB } \\
(n=47)\end{array}$ & $P$ trend \\
\hline hs-cTnI, pg/mL & $12(0-54)$ & $21(0-170)$ & 0.019 \\
\hline $\mathrm{CK}-\mathrm{MB}, \mathrm{ng} / \mathrm{mL}$ & $1.52(0.81-2.40)$ & $2.31(1.23-4.00)$ & 0.021 \\
\hline NT-proBNP, pg/mL & $477(222-1634)$ & $609(127-1290)$ & 0.678 \\
\hline Total cholesterol, mmol/L & $2.39(1.88-2.87)$ & $3.69(3.35-4.36)$ & 0.668 \\
\hline LDL cholesterol, $\mathrm{mmol} / \mathrm{L}$ & $2.40(1.87-2.45)$ & $2.41(1.97-2.74)$ & 0.989 \\
\hline HDL cholesterol,mmol/L) & $0.91(0.79-1.08)$ & $0.86(0.71-0.99)$ & 0.193 \\
\hline Triglycerides (mmol/L) & $1.55(0.98-1.74)$ & $1.19(1.01-1.57)$ & 0.403 \\
\hline WBC count, $\times 10^{9} / \mathrm{L}$ & $6.50(4.41-8.50)$ & $6.15(4.45-8.12)$ & 0.692 \\
\hline Neutrophil count, $\times 10^{9} / \mathrm{L}$ & $4.50(3.12-7.85)$ & $4.40(2.72-6.62)$ & 0.506 \\
\hline hs-CRP, mg/L & $57.8(7.5-135.5)$ & $53.4(18.9-102.9)$ & 0.921 \\
\hline Procalcitonin, ng/mL & $0.075(0.038-0.220)$ & $0.091(0.032-0.184)$ & 0.921 \\
\hline Lymphocyte count, $\times 10^{9} / \mathrm{L}$ & $0.90(0.65-1.18)$ & $1.08(0.54-1.50)$ & 0.468 \\
\hline Monocyte count, (\%) & $6.90(3.55-8.73)$ & $7.60(3.40-10.10)$ & 0.659 \\
\hline Platelet count, $\times 10^{9} / \mathrm{L}$ & $210(157-290)$ & $192(133-274)$ & 0.492 \\
\hline Prothrombin time, s & $12.40(11.83-12.80)$ & $12.10(11.60-13.10)$ & 0.899 \\
\hline APTT, s & $27.6(24.8-30.7)$ & $27.7(26.2-32.8)$ & 0.256 \\
\hline D-dimer, mg/L & $1.42(0.51-4.93)$ & $1.96(0.66-15.90)$ & 0.350 \\
\hline $\mathrm{ALT}, \mathrm{U} / \mathrm{L}$ & $26(17-59)$ & $25(16-51)$ & 0.747 \\
\hline AST, U/L & $32(20-45)$ & $32(22-51)$ & 0.568 \\
\hline Total bilirubin, $\mathrm{mmol} / \mathrm{L}$ & $14.00(10.30-18.75)$ & $8.90(6.10-15.20)$ & 0.004 \\
\hline Blood urea nitrogen, $\mathrm{mmol} / \mathrm{L}$ & $5.90(4.45-8.69)$ & $5.50(3.80-10.90)$ & 0.952 \\
\hline Creatinine, $\mu \mathrm{mol} / \mathrm{L}$ & $65.0(56.5-75.0)$ & $70.0(48.0-112.0)$ & 0.304 \\
\hline eGFR & $90.5(65.3-7-95.4)$ & $84.2(52.2-100.3)$ & 0.868 \\
\hline $\begin{array}{l}\text { Bilateral distribution of patchy } \\
\text { shadows or ground glass opacity }\end{array}$ & $23(100)$ & $46(97.9)$ & 0.481 \\
\hline
\end{tabular}

ACEI/ARB: Angiotensin-converting enzyme inhibitors/angiotensin receptor blockers; ALT: Alanine aminotransferase; AST: Aspartate aminotransferase, APTT: Activated partial thromboplastin time, CK-MB: creatinine kinase-myocardial band, eGFR: Estimated glomerular filtration rate, HDL: High density lipoprotein, hs-CRP: High-sensitivity C-reactive protein, hs-cTnl: highsensitivity cardiac troponin I, IQR: interquartile range, LDL: Low density lipoprotein, NT-proBNP: N-terminal pro-B-type natriuretic peptide, WBC: White blood cell. 